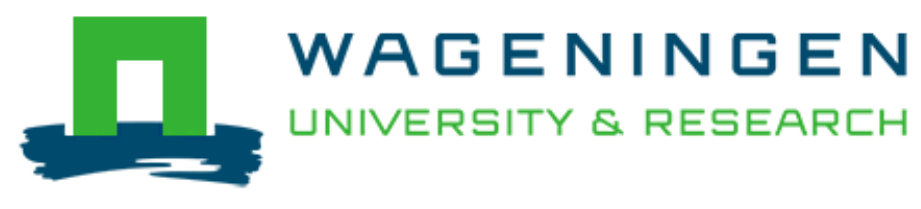

\title{
Pesticides and the Patent Bargain
}

Timmermann, C. A.

This is a "Post-Print" accepted manuscript, which has been published in "Journal of Agricultural and Environmental Ethics"

This version is distributed under a non-commercial no derivatives Creative Commons (c) (1) $(9)$

(CC-BY-NC-ND) user license, which permits use, distribution, and reproduction in any medium, provided the original work is properly cited and not used for commercial purposes. Further, the restriction applies that if you remix, transform, or build upon the material, you may not distribute the modified material.

Please cite this publication as follows:

Timmermann, C. A. (2015). Pesticides and the Patent Bargain. Journal of Agricultural and Environmental Ethics, 28(1), 1-19. https://doi.org/10.1007/s10806-014-9515-x 


\title{
Pesticides and the patent bargain
}

\author{
Cristian Timmermann
}

Jacques Loeb Centre for the History and Philosophy of the Life Sciences

Ben-Gurion University of the Negev

P.O. Box 653

Beer Sheva 84105

Israel

Philosophy Group, Wageningen University

Hollandseweg 1

6706KN Wageningen

The Netherlands

cristian.timmermann@gmail.com

\begin{abstract}
In order to enlarge the pool of knowledge available in the public domain, temporary exclusive rights (i.e. patents) are granted to innovators who are willing to fully disclose the information needed to reproduce their invention. After the 20 -year patent protection period elapses, society should be able to make free use of the publicly available knowledge described in the patent document, which is deemed useful. Resistance to pesticides destroys however the usefulness of information listed in patent documents over time. The invention, here pesticides, will have a decreased effectiveness once it enters the public domain. In some cases pesticides lose most of their efficacy shortly after temporary exclusive rights expire. Society's share of the patent bargain - having new useful knowledge available in the public domain - is lost. Resistance can be slowed down, if pesticide use is limited by optimal compliance. Stimulating proper use is generally not compatible with existing market incentives for patent holders, since these have to be able to maximize profits in order to recoup research and development costs and satisfy obligations to the company's stakeholders. Another incentive system is needed to ensure longevity of pesticides, which at the same time does not hamper future research.
\end{abstract}

Keywords: pest management; pesticide effectiveness; common heritage of humankind; intellectual property; social justice 


\section{Introduction}

Patents are tools established by society to stimulate innovation while maintaining a balance between public and private interests. Temporary exclusive rights (i.e. patents) are granted to innovators who are willing to fully disclose the information needed for the invention to be reproduced by someone skilled in the art. Society gains with the enlargement of the pool of knowledge freely available in the public domain after the 20 -years patent protection period elapses. Temporary exclusivity allows innovators to recoup research and development costs as well as to make some profits provided the invention finds a large enough market. This trade-off has been called the patent bargain (Biagioli 2006). The public gains useful knowledge, which will be freely available after the expiration of the patent, and private parties have the opportunity to engage in lucrative inventive endeavours.

Pesticides challenge this public-private bargain. As pesticides are released into the open, the habitat changes and many pests develop resistance to pesticides. Open exposure makes the active agent less useful or even useless as time goes by. While private parties enjoy temporary exclusivity to the full extent, society gains knowledge that may be of little use once these patents expire, depending on the pace pests develop resistance. Knowledge related to pesticides is "consumed" or "perishes".

The resulting situation raises a wide range of concerns for justice. To elaborate upon them, I will (1) introduce the idea of the patent bargain and the instrumental role of patents, (2) explain what is meant with "perishable knowledge", (3) examine what patent holders actually own, (4) analyse four possible scenarios on loss of pesticide effectiveness, (5) analyse how our current policies with regard to pesticide resistance creates two additional undesirable incentives, and as a conclusion (6) discuss the unjust outcome for the global poor and future generations.

\section{The patent bargain}

There is a tendency to see patent rights as natural rights. Under this view, inventors have a right to the fruits of their intellectual labour following Lockean theories of property. In this tradition differences in opinion exist in how far the scope of these rights extends: some claim an absolute right, others content themselves with a fair return on labour (cf. Sterckx 2005).

Law has from early on taken distance from the idea of absolute rights for intellectual property and maintained this space in several international agreements thereafter. To name an early example, an instrumental understanding of patent rights can be found in a highly influential legal text, the Constitution of the United States of America (1787). This constitution grants the US Congress the power "To promote the Progress of Science and useful Arts, by securing for limited Times to Authors and Inventors the exclusive Right to their respective Writings and Discoveries" (art. 1, section 8). The US Constitution seeks to promote science by securing exclusive rights - endorsing natural rights would mainly demand to secure these exclusive rights, the prospect that science would be thereby promoted is merely circumstantial.

Nowadays, the mainstream view on intellectual property rights also maintains distance from the natural law tradition. In article 7 of the Agreement on Trade-related Aspects of Intellectual Property Rights (1994, hereinafter TRIPS) we can read: "The protection and enforcement of intellectual property rights should contribute to the promotion of technological innovation and to the transfer and dissemination of technology, to the mutual advantage of producers and users of technological knowledge and in a manner conducive to social and economic welfare, and to a balance of rights and obligations." The principle of absolute rights is incompatible with the concepts of "balance of rights" and "mutual advantage". 
It is important to note that human rights law demands the protection of material interests of innovators. ${ }^{1}$ However, no specifications are given to what extent those interests are to be protected. As human rights law also protects a right to benefit from scientific advancement (UDHR, art. 27.1 and ICESCR, art 15.1(b)), a protection of the full material interests cannot be sustainably secured. Innovators thus only have a right to secure some of their material interests. Summarizing in one sentence: patents are designed for the benefit of both technology users (the interests of the public at large) and technology producers (private interests).

Exclusive rights are not only balanced by other social interests, but also confined in time. Perpetual rights would make the clearing of licences to further innovate and market research output prohibitively expensive. In the case of patents, an arbitrary time segment was chosen to allow inventors to recoup research and development costs - 20 years is currently the global standard (TRIPS, art. 33). This works to the advantage of some and to the detriment of others. In the case the 20-year time period is not sufficient to recoup extensive research and development costs as well as sufficient profits, often direct government funding is the solution, as is exemplified with the funding of basic research. Many research areas remain however underfinanced - which may lead to a shortage in technological solutions, an outcome that has caused major public discontent when it comes to medicines for tropical diseases (cf. Timmermann and Belt 2013).

After the 20-year patent period the invention is free to be exploited by the public. This is made possible by the patent applicant's obligation to submit a document enlisting all necessary information for someone skilled in the art to be able to carry out the invention. The existence of a generic industry is thus a premeditated and desired outcome and not a result of sheer opportunism.

The information entailed in patent documents is considered useful and substantial efforts are made by patent offices, commercial institutions and non-profit organizations to increase the number of patent literates. ${ }^{2}$ As the World Intellectual Property Organization (2013) states:

"All patent owners are obliged, in return for patent protection, to publicly disclose information on their invention in order to enrich the total body of technical knowledge in the world. Such an ever-increasing body of public knowledge promotes further creativity and innovation in others. In this way, patents provide not only protection for the owner but valuable information and inspiration for future generations of researchers and inventors."

There is a strong claim on future benefits in this statement. This passage also implicitly welcomes future creativity. Inventions that are meant to be sold above cost price have to have new or additional characteristics that competing generic products do not have in order to attract customers.

The idea that future work builds on today's research has been acknowledged for centuries we may just recall the often-cited phrase attributed to Isaac Newton: "If I have seen far, it is by standing on the shoulders of giants." It is therefore safe to say that anyone claiming absolute ownership on her "own" ideas will find herself disputing with a well-anchored opposition.

\section{"Perishable" knowledge}

As mentioned, society should be able to freely use the publicly available knowledge in patent documents after the 20-year exclusivity period elapses and the knowledge encompassed in patent documents is considered useful enough to justify the temporary monopoly right. This trade-off makes sense only when patented knowledge retains certain usefulness. Here it becomes important to draw a distinction between retaining the monetary value of an invention and preserving the effectiveness of an invention. The monetary value is generally determined by demand and availability of alternatives. A

\footnotetext{
${ }^{1}$ See Universal Declaration of Human Rights (1948), hereinafter UDHR, art. 27.2, International Covenant on Economic, Social and Cultural Rights (1966), hereinafter ICESCR, art. 15.1(c) and UN Committee (2006).

${ }^{2}$ E.g. The Patent Lens (www.lens.org), see Jefferson et al. (2013)
} 
pesticide is valued higher when there is a pest outbreak and even higher, when no other alternatives are available to combat the pest. Technical development, especially when driven by high competition, significantly reduces the monetary value of older inventions by providing additional and improved alternative products and methods. Normally, technical development only affects the effectiveness of older inventions in relative terms and not in absolute terms. It is generally assumed that competing inventions only affect the monetary value of older products not their absolute effectiveness.

The development of resistance against pesticides, however, creates a different situation. Over time the pests' resistance to pesticides destroys the usefulness of information listed in patent documents. The invention, here pesticides, will have a decreased effectiveness once it enters the public domain. In such cases knowledge is said to be "consumable" (Outterson 2005) or to entail a "perishable technology" (Lema and Lowenstein 2008). Reformulating the above-mentioned metaphor, we can say that the giants, on whose shoulders the pesticide industry stands, have their feet on sinking ground. The loss of pesticide effectiveness is not just an instance of depreciation or reduction of monetary value. Such labels are philosophically hard to digest and therefore deserve further analysis.

First, we need to know what happens to the knowledge described in patent documents. Knowledge contained in patent documents describes a specific state of affairs at a time necessarily occurring before a technology is widely available and used. The invention has to be new to qualify for a patent, thus making its previous inexistence mandatory (TRIPS, art. 27.1). Economic literature mostly assumes that the knowledge held in patent documents will be unaffected from the day of application to the day where exclusive rights elapse. It is generally assumed that knowledge is of nonrivalrous consumption (Stiglitz 2008) - it can be enjoyed by multiple people without lessening it.

To gain an understanding of the problem of "consumable knowledge" let us analyse the wording of a classic pesticide patent: Paul Müllers' invention of processes to make dichlorodiphenyltrichloroethane (DDT) and the discovery of insecticidal uses thereof. The US patent number 2,397,802 titled "Insecticidal compound and a process of making same" was granted by the US Patent and Trademark Office in April 1946, after being first filed for patent in Switzerland 1939. The claims to the patent refer to the process of making the compound and the compound itself - knowledge that retains its validity over time. What makes this knowledge commercially and socially valuable is its application: the discovery of the insecticidal properties of the compound. Paul Müller refers to a number of examples concerning the insecticidal use of the compound. Let us review the language used in the examples, it is said that the compound:

- “... possess strong insecticidal properties"

- "... by spraying moths, plant lice and other pests are annihilated within short time..."

- “... of good insecticidal efficacy..."

- “... is poisonous for insects..."

- "... react[s] on insects as food poison and also as contact poison"

"... kill[s] insects even in slight concentration"

“... possess strong insecticidal properties"

The choice of words in the patent document reveals that the efficacy of the product varies. Müller does not claim a success rate for all species nor for a species in its totality. The examples merely state that the compound will have the intended reaction in an - one should assume cost-effective - number of cases.

It is important to gain a good understanding of this cost-effectiveness assumption. Examining where this threshold lies is essential for finding out if society is losing its side in the patent bargain. An early study made in the 1960s reveals that for every dollar spend on pesticides the farmer will gain four dollars worth in increased harvest rates (Headley 1968). Resistance has considerably reduced this number and there is an increasing demand that negative externalities to the environment should be deducted as well (cf. Carlucci 1994; Waibel et al. 2003). Externalities are hard to quantify as we have learned from efforts to estimate the negative effects on soils and water organisms (cf. Damalas and Eleftherohorinos 2011). 
Summarizing we can say that cost-effective means that the increased harvest should provide sufficient income to pay for the pesticide, its application, monitoring and any negative externalities the farmer could be held accountable for or wishes to take into consideration. The public loses its share when pesticides resistance has increased to such levels that their application is not profitable anymore after costs have been subtracted. Hence, the knowledge whose truth-value changes over time can be generalized in the following phrase:

agent $x$ will have a reaction $r$ in $y$ percentage of cases

But, what exactly happens with this information?

Once a pesticide is routinely and massively released in the environment the target organism and the ecosystem hosting it react. Depending on the targeted organism, strains less vulnerable to the pesticide will slowly or rapidly take over the habitat occupied by the more pesticide-sensitive strains of the same organism. The strains resistant to the pesticide survive and vulnerable strains of the pest perish (cf. Palumbi 2001). Problematic for the patent bargain is that both strains of the target organism usually share the same name. A name in biology denotes a group of sufficiently similar but nonidentical objects or beings. Thus, when one of the uses of the technology specified in the patent document affirms that it will kill the target organism, the patent holder makes only reference to the strains prevalent at the time of patent application - the moment before massive exposure. After exposure the same biological name will be used for the target organism's offspring. Yet these will have in their totality slightly different traits and widely lack the essential characteristic of pesticide vulnerability.

As a second problem, pests are a part of an ecosystem and attacking them may cause a series of reactions that we can hardly predict. Pest systems have high resilience (Holling 1973). Resilience as most broadly defined is the capacity of an ecosystem to recover after the intrusion of an alien agent. The state to which it bounces back is however not exactly the same state as the one before the intrusion. There is a variation, in some cases only a mild one, but the ecosystem is definitely not the same after the perturbation. What this means for patent documents is that a description of the ecosystem before the perturbation is necessarily different than a description of the system after the intrusion. If you have patented knowledge, this knowledge is related to the state of the system before the perturbation. As the agent that causes the change is present in larger numbers, the state assumed to be prevalent in the patent document starts to become increasingly rare. ${ }^{3}$ The effect on the ecosystem is even larger when pesticides are carelessly administered killing a large number of non-target organisms (Pimentel et al. 1992). Putting the agent into the open will cause a change in the environment, transforming the environment to one that is often not sufficiently identifiable with the one assumed to exist in the patent document. Due to the complexity of ecosystems, it is prohibitively expensive or even impossible to complement a patent document with all potentially relevant information about the destination environment.

TRIPS agreement article 29.1 obliges patent applicants to disclose all information for someone skilled in the art to carry out the invention. This disclosure is made at the time of patent application and there is generally no legal requirement to update this information. If the pesticide is a chemical compound, we can expect that information concerning the pesticide itself does not become obsolete. The element that changes is necessarily the environment or the target organism. The information about the environment in the patent document is incomplete if it becomes obsolete over time.

A claim that states that an agent $x$ will have a reaction $r$ in $y$ percentage of cases will not retain its truth value unless it is accompanied by a formula that reduces the value of $y$ over time. The updated information on the invention may well be of no societal use once the patent expires (e.g. agent $x$ is useless to kill the targeted pest). As mentioned, the list of information that could affect the invention is

\footnotetext{
${ }^{3}$ In the words of Böhme et al. (1976): “... it is precisely the repetition of the experiment that has invalidated the proposition that DDT is an insecticide since its being repeated has led to the selection of resistant insect strains."
} 
in no way exhaustive, nor can it reasonably be. Even, if the information contained in the patent document is complete we still have to ponder if as a society we should grant exclusive rights over an invention that is only temporarily useful.

\section{What does the patent holder own?}

Pesticide resistance plays a major challenge to fulfil industry's half of the bargain and not only that: it creates an additional hurdle to establish a just society. Traditionally patents are granted to allow the inventor to exclude others from making unlicensed use of the invention she can legitimately claim as her own (cf. Radder 2013). Similarly as with property rights over tangible objects the patent owner has a legitimate claim to exclude others from using the object in question (cf. Wenar 2011). Phrased in terms of ownership, the patent holder owns the right to exclude others from making unlicensed use of the invention for twenty years. If a knowledge set becomes a good of rivalrous consumption, society might be handing over something more than mere temporary exclusivity by granting patents. We have to analyse what is it society is granting exclusive rights for.

Borrowing from the literature on antibiotics resistance, we can theorize on the distinction James Wilson (2013) and Jasper Littmann (2014) draw between owning the effectiveness of an invention and having exclusive rights over the use of the same invention. Making this distinction has no significance for traditional technologies, since these retain their effectiveness. However, for inventions that lose their effectiveness over time, as is the case with pesticides, it becomes necessary to understand this distinction and its societal implications. Loss of pesticide effectiveness may not only undermine the patent bargain but also continuously deprive the poor and come at a significant cost for future generations. ${ }^{4}$

It is often assumed that granting innovators temporary exclusivity over the use of their invention does not harm future generations. This assumption is subject to two important provisos. One, exclusive rights are not used to block competitors and thus slow down socially valuable innovation (the so-called "destructive" use of patents, see Schneider 2010). Two, we have to ignore the possibility that future generations will develop a lasting moral revulsion for our generation having let millions of people die and suffer because of policies that maintain medicines as well as other vital innovations artificially scarce. High markup prices for branded pesticides may continuously impede access for poor farmers.

As mentioned earlier, inventions are regularly superseded while not losing their usefulness in absolute terms. To give an example, a wealthy farmer will most likely not harvest large fields with a sickle, since large machinery makes this task so much easier. The sickle however still cuts grain as it always has. An inventor who wants her new invention to be bought at a higher price than existing competing products has to offer something with more appealing qualities, thus reducing the relative utility of preceding inventions.

The effectiveness of an invention often depends on the social and natural environment the invention is embedded in. Pharmaceuticals may fall into disuse when equivalent medicines that have less negative side-effects become available. Military technologies constantly supersede each other. Every new attack or camouflage invention induces researchers to find a new method to defend oneself from threats or detect intruders. The advantage of acquiring an electronic equipment is highly dependent on the type of electronic equipment others are using (cf. Bessen and Meurer 2008). Many technologies become obsolete once creative minds counter their potential with other new inventions designed to outmatch them.

Assuming biotechnology producers are drawing from a never-ending source of possibilities to combat pests, the harm caused by loss of pesticide effectiveness triggered by profit maximization

\footnotetext{
${ }^{4}$ Without going into the philosophical complexities related to future generations (cf. Gosseries and Meyer 2009), I will take for granted that: (1) society has a general interest in future generations to exist (in procreation) and (2) if the present generation decides to procreate it should not make for future generations the enjoyment of a good life more difficult than it is for the present generation.
} 
would be partially remediable for future generations. However if the opportunities to develop further pesticides are continuously reduced or become prohibitively expensive, avoiding pesticide resistance becomes imperative. The number of chemical compounds industry has to screen before finding a costeffective pesticide has risen drastically. New technologies have considerably reduced the costs of screening chemical compounds, but increased knowledge about the negative effects of pesticides to the environment and human health obliges researcher to disqualify an increased number of potential chemicals for commercial use (Berenbaum et al. 2000; den Hond 2003). The rapid loss of biodiversity will be an additional factor affecting the number of biopesticides that can be made available in the future (cf. Glare et al. 2012).

While in the following we will focus on future effectiveness, it is important is to keep in mind that the poor will be continuously deprived from access to effective pesticides when generic variants are not available - this affects food security. ${ }^{5}$ Unilateral appropriation of pesticide effectiveness therefore can harm to the poor, the consequences of which we will discuss in the concluding section.

\section{Pesticide effectiveness as common heritage of mankind}

A number of resources are considered common heritage of humankind and this for two major reasons. One, no person or group of individuals can legitimately claim ownership over these resources. And two, under a veil of ignorance ${ }^{6}$ rational people would not agree on a social contract that would assign exclusive rights over these resources to third parties. Often cited examples of such resources are the ozone layer, biodiversity, cultural heritage, outer space and oceans (cf. Chemillier-Gendreau 2002; Brody 2010). Merely stating the keywords chlorofluorocarbon, biopiracy, Bamiyan valley Buddha statues, space debris and overfishing, gives a solid picture of problems around common ownership. Pesticide effectiveness can be added to the list of resources held in common by humanity.

Adding chemical pesticides to this list may bring on the objection that these objects are not randomly available in nature but developed and manufactured by industry and public institutions. ${ }^{7}$ Since the inventors bring these objects into existence they are not depriving anyone in the sense of "dispossessing" them. ${ }^{8}$ These inventions are not created ex nihilo; it is more appropriate to talk about discovering specific traits of chemicals. Even in cases of complex chemical synthesis, inventors are still depriving future people from a maybe limited source of chemical compounds with cost-effective pesticidal characteristics.

In the case of biopesticides, industry is drawing directly or indirectly from a very large pool of biological resources. The fact that scientists are only beginning to tap this tremendous pool of possibilities, should not serve as an excuse to treat this pool as inexhaustible on a normative level. As products of nature, biopesticides can still be patented in synthetized form in most jurisdictions. Processes to make these biopesticides available on large scale can be patented as well (Montesinos 2003). Smallholders are already paying much higher prices for traditional pest control due to the sudden increase in demand for biological materials on which these biopesticides are based upon, as the case of neem-based insecticides illustrates (Khater 2012). Many biopesticides are currently produced

\footnotetext{
${ }^{5}$ Between 20 to $40 \%$ of crops are currently lost due to pests and diseases, see Popp et al. (2013).

${ }^{6}$ This refers here to the case where people do not know if they are members of the generation that exchanged the resource for a set of benefits or are offspring of the generation who already consumed whatever benefits received in exchange.

${ }^{7}$ On the related case, Orzech and Nichter (2008) note that "Antibiotics are not a "global public good" because they are privately developed, manufactured, sold, and managed according to the profit motives of pharmaceutical companies."

${ }^{8}$ As an objection, it is often claimed that pesticides would not have been developed if exclusive rights were not enforced to secure sufficient returns for those who develop them. We cannot deprive the poor from something that would actually not exist without exclusive rights. This claim is not necessarily true. Many important inventions were developed without making use of exclusive rights (e.g. for antibiotics see Quinn (2013)). At the most one could argue that some pesticides would have been developed at a later stage.
} 
by small-scale farmers without the need of complex equipment. If the next generation of biopesticides have to be acquired from a specialized industry, small-scale farmers will lose part of their independence. Exclusive rights on both chemical pesticides and biopesticides raise a number of problems.

It is worthwhile to note that the principle of common heritage of humankind embraces a profoundly utilitarian element, which is most evident when it comes to cultural goods. A well-known example is the case of Kafka's unpublished manuscripts. Franz Kafka left Max Brod his unpublished work with the explicit request of destroying these upon his death. Brod refused to fulfil his friend's will and published a number of Kafka's texts. Thanks to his refusal humanity inherited the literary masterworks "The Castle" and "The Trial", as well as other pieces. While failing to honour a dead person's will is generally condemned by society, few denounce Brod's decision (cf. Strahilevitz 2005; Butler 2011). Public interests can override traditionally reserved moral interests of authors and inventors - another clear departure of the natural rights tradition.

Yet, even among items that are considered common heritage of humankind, we may have good instrumental reasons to acknowledge certain rights over discoveries, productions or conservations. In addition, some rights or privileges may be argued for based on notions of desert or just reward (cf. De Jonge 2011). Here we should be attentive that rights that lead to overexploitation are not compatible with utilitarian reasoning or the idea of a fair return on labour invested (cf. Donselaar 2009).

In the following we will analyse under which circumstances rational people would recognize exclusive rights over pesticide effectiveness in a veil of ignorance situation - the theoretical situation where people decide while not being aware if they are born rich or poor, today or in a century.

The number and types of cost-effective pesticides that can be developed in the future are unknown; we will therefore give a moral evaluation of four possible scenarios. Loss of pesticide effectiveness can be classified in four types. A pesticide can become inefficacious when:

(1) the target organism is fully eradicated without side-effects

(2) the target organism was only temporary controlled, but new options to develop pesticides are available that are equally or less costly

(3) the target organism was only temporary controlled, but developing new pesticides is now more expensive

(4) the target organism was only temporary controlled, leading to a reduction of the overall number of pesticides that can be cost-effectively developed

Let us examine the consequences of each scenario one by one.

In the first scenario the pesticide does not become inefficacious but rather irrelevant. The knowledge related to the invention lost its utility because the mission it was developed for has been accomplished. In this case we can say that instead of offering society useful knowledge entering the public domain, the inventor made a new global public good available: the eradication of a threatening pest - a trade-off society generally welcomes. The only identifiable harm to single individuals is seeing one's chances of becoming the next Paul Müller shrink - conserving such opportunities cannot be defended using any major moral reasoning.

The second scenario is the case where the pesticide acts only as a temporary solution without causing negative side-effects for future generations. However, we still may ask: Are researchers who spend limited resources (research time) in solutions that are by nature suboptimal harming future generations or the poor? To prove harm in this case inevitably confronts us with the old philosophical question of "does can imply ought?" - do researcher have the moral duty to work on pesticides that have an increased durability? The answer will vary strongly depending on the supported ethical tradition. To limit the length of the article we will only concentrate on one tradition, by focussing on a perspective that incorporates a sum of moral values: the Universal Declaration of Human Rights. A lengthier deviation of the central argument is here necessary - my apologies to the reader. 
Article 27 of the UDHR deals with the human right to benefit from scientific advancement (cf. Marks 2011; Timmermann 2014b). While this article has been traditionally used to claim broader access to the objects of innovation, it is difficult to see if an orientation to more useful scientific advancement can be clearly argued for based on this article (cf. Chapman 2009). The exact wording of the relevant section of the article - endorsing a right "to share in scientific advancement and its benefits" - leaves open the direction science should take. This section does not allow much more interpretation than a right to whatsoever benefits an advancing science is yielding. At the time the declaration was written it was believed that the best for society would be to have science free from state interference. ${ }^{9}$ In part this was due to the recent dramatic post-war experience exemplifying how science and technology can be used to augment destruction. The idea of distancing science from political agendas however seems to have been prevalent before the biggest catastrophes of World War II came to light (or darkness so to say). To name a famous example, Robert Merton promoted the scientific virtue of disinterestedness as part of his highly influential scientific ethos (cf. Merton 1942; Belt 2010) - an ideal that portrays the scientists' central duty to be the search for truth, guided by altruistic concerns but clearly maintaining distance to institutions and motives that may interfere or mislead the scientists' quest for truth. Ensuring scientific freedom was seen as paramount in the early post-war period and allowing political interference was seen as a risk that outweighs potential benefits. Times have however changed. Scientists have largely accepted that they have to follow interests dictated by broader government or regional research agendas and are nowadays obliged to attract the interest of large corporations if they want to continue their career (cf. Macfarlane and Cheng 2008). The pursuit of truth has become exponentially expensive and scientists are nowadays more open to make commitments to the public and industry in order to get larger amounts of funding (cf. Stephan 2012). In general we can say that scientists have become more willing to follow political agendas.

In relation to food, human rights law gives a clearer standpoint towards where science agendas should ideally set their direction to, while still refraining from specifying duties. The International Covenant of Economic, Social and Cultural Rights (1966) urges States to improve food production with the help of science and technology, individually and through international cooperation (art. 11.2.a). This article does not imply that science should not indulge in other areas of research, however the principle of progressive realization (art. 2.1) does not allow retrogression. We can interpret out of the two articles an obligation to at least maintain overall pest control capacities. Pesticide dependence demands further research to counterbalance the loss of effectiveness in order to maintain harvest yields. This is a particularly troubling outcome when traditional knowledge on pest management techniques is lost due to disuse, leading to continuous dependency on industrial innovation (cf. Gliessman 2007).

Even if science could continuously counter pesticide resistance by developing new pesticides, we may have good reasons based on human rights principles to push forward conservation measures. Many constitutions and bills of rights justify their existence for the sake of sustaining (and often also improving) welfare. The metaphor of the "pesticide treadmill" portrays the situation where science is not being advanced in absolute terms (cf. Goeschl and Swanson 2003); allocating resources to "run in a treadmill" is hard to justify. If the promotion of welfare is an imperative, we should realize that research time is a scarce resource, taking an appeal to promote welfare seriously has to come hand in hand with a wiser allocation of research efforts (Timmermann 2014a). Science should therefore focus on long-lasting solutions and policies will have to sustain the effectiveness of technologies that have been developed.

\footnotetext{
${ }^{9}$ We can read in the transcript of a drafting session held November 1948: "The Australian delegation would be unable to accept the USSR amendment which subordinated scientific research to a political principle [i.e. the promotion of peace]; the sole aim of science could only be the quest for truth..." (United Nations 1948b). The reluctance to follow a political principle is easier to understand after contrasting it with the perspective of the Peruvian delegation "... not only must the right of every person to take part in the cultural, artistic and scientific life of the community be recognized, but also the right to do so in that complete freedom without which there could he no creation worthy of man", thereafter recalling the harmful political pressures to scientists in recent history (United Nations 1948a).
} 
We are thus left with two extremes: to retain the current status quo, the situation where the first one to file a patent can grasp as much benefits from a common-pool resource for twenty years as she sees fit or the other extreme of condemning private parties for offering solutions of temporary nature. A right balance between the two extremes has to be struck. Unfortunately, finding where this balance exactly lies has to be left for future work.

Moving on with the third scenario, we have the case where the pesticide losses its efficacy and substituting pesticides are more expensive to develop (even after any justifiable future discounting). We can say that future generations are relatively worse off compared to people living today in regard to developing protection measures against pests. The high prices maintained by patents will also leave the poor continuously empty-handed or under a considerable burden. In this case patents will serve as a tool to continuously hijack a resource that can be considered as common heritage to humankind.

In how far this seizure is from an ethical point of view defensible, depends on what is being offered in exchange for the appropriation of pesticide effectiveness. Public goods from which the global poor and future generations can benefit could offset the negative effects of the appropriation. There are strict limits on this trade-off, as food security cannot be jeopardized. It is obvious that if hunger or severe malnutrition is prevalent even public goods cannot be enjoyed. In a limited number of cases, the making available plant varieties with increased pest resistance could count as a legitimate trade-off.

The fourth and last scenario is especially condemnable as it describes limits of future capacities to react to pests. It represents the worst-case scenario indicating that we are drawing from an exhaustible pool. Some claim that society should not worry about future possibilities to develop new chemical pesticides due to the enormous possibilities of synthetizing new compounds (Stetter and Lieb 2000). We should however not blindly assume that future compounds will be able to combat pests in a cost-effective and environmentally responsible manner. Further, in a world of extreme inequalities it is highly unlikely that humanity will agree on a set of parameters to define what is prohibitively expensive and what is not. Since the possible consequences of overestimating future possibilities to combat pests could be catastrophic, we should examine this alternative outcome as well.

Assigning third parties exclusive rights to exploit an exhaustible resource is especially problematic when long-term human survival depends upon these resources. Granting temporary exclusive rights over an exhaustible resource must bring clear benefits to those who will not be able to profit from such arrangement. As is well-known, we currently consume a number of non-renewable resources, something that has been repeatedly condemned by referring to the interests of future generations. As mentioned earlier, one way to counter this injustice is to offer compensation in the form of non-consumable public goods. Using fossil fuels to advance science could up to a certain degree count as an acceptable quid pro quo. Yet, it is obvious that such trade-offs cannot be continuously made and have certain limitations. Biodiversity loss is a popular example. It is difficult to believe that future generations will consider the immense loss of biodiversity as an acceptable trade-off for the wide range of consumer goods that have become available. In addition, future generations may find much better uses for resources that have been nearly exhausted and therefore value these much higher than we currently do (cf. Singer 2004). We may overestimated the potential scientific advancement has in offering solutions to withstand pests with catastrophic consequences for human welfare in the future.

The challenge in this scenario is to make a clear case that we are harming future generations. Condemning actual practices gains in strength when we can prove that we are not only placing future generations in a relatively more difficult position, but that we are actually jeopardizing their survival. Increased burdens are regularly subject to future discounting. To phrase in an extreme manner: we cannot future discount when there is no future population capable of feeding itself.

As we have seen, the strong link to food security makes the maintenance of future pesticide effectiveness a far-reaching social concern. An additional incentive system is needed to ensure the longevity of pesticides. Failing to sustainably steward pesticide effectiveness continuously deprives 
farmers from generic pesticides and may increase the difficulties to combat pests for future generations.

\section{Pesticide effectiveness stewardship}

Resistance to pesticides can be slowed down with integrated pest management systems, where pesticides play a less dominant role. Under some circumstances market incentives encourage conservation, in others cases we can observe that market incentives support reckless exploitation. ${ }^{10}$ Patent holders acting as economically rational agents are only incentivized to ensure proper use when fears exist that resistance to pesticides will build up significantly during the patent's lifetime. As we can observe in the related case of plant varieties which have Bt (Bacillus thuringiensis) genes inserted, seed companies can oblige farmers to take measures to slow down resistance through contracts (cf. Noonan 2003; Frisvold and Reeves 2010). In this particular case, motivated by economic interests, the patent holder pushed for the enforcement of measures to slow down pest resistance.

Distinct is the case when resistance builds up significantly only after the patent expires. As is well-known, economically rational behaviour dictates profit maximization in order to recoup research and development costs and satisfy obligations to the company's stakeholders. As a consequence companies will rationally choose to maximize sales throughout the exclusivity period while taking time discount rates into consideration (i.e. one euro today is more worth than one euro tomorrow).

Correct choice of pesticide, timing and dosage can greatly reduce the building up of resistance. Education in pest management has to be undertaken globally to maintain the global public good of pesticide effectiveness for a longer time. Educating involves costs and will have to be directed toward reducing pesticide resistance (cf. Lenné 2000). If we consider pesticide effectiveness a global public good, it is perhaps not fair, maybe also not reasonable, to make solely the agrochemical industry responsible for teaching farmers how to slow down pesticide resistance.

Are pesticide producers suitable educators? Agrochemical companies earn money with pesticides of good reputation: basically on how farmers think the pesticide will perform, not for the actual performance. As long as the reputation of a pesticide stays untouched while exclusive rights over it are held, isolated poor performance is not a problem the company has to worry about. Companies benefit financially if the farmer is using more pesticides than needed, especially if true dosages are underreported or not disclosed. The biotechnology companies have multiple conflicts of interests when instructing on proper use. Similarly, one could also question the accuracy of some farmers' reports on pesticide use when consumers are increasingly demanding more ecological products and when they are being held accountable for environmental pollution.

Further, concerning the issue of fairness, arguments stating that we should not overburden innovators are sound. Intellectual property places almost the full costs of failure to the innovator. If the invention does not find a large enough market, bankruptcy may follow. Making a research area overly risky jeopardises future supply. Especially inventive small- and medium sized enterprises, which are an essential element for the advancement of social prosperity, already assume huge burdens.

As a general measure to slow down pesticide resistance, governments can help by offering affordable crop insurances. If the financial stakes of crop destruction are too high, overuse of pesticides will be often a consequence of fear. Affordable crop insurance has to be available worldwide to reduce pesticide dosages driven by unwarranted fears.

\section{Two additional misplaced incentives}

Technologies that become useless after their patents expire can lead to significant benefits for the industry that develops them. Farmers will not buy generic pesticides if these are inefficacious and thus

\footnotetext{
${ }^{10}$ Again, relying on the literature on antibiotics, an overview of different strategies to combat resistance is offered by Outterson (2014).
} 
will have to continuously pay the much higher prices of branded pesticides. In a globalized world with highly competitive markets and where only a limited number of farmers have sufficient purchasing power, this is a highly welcomed outcome for the agrochemical industry (cf. De Schutter 2009). As competing pesticides get weaker over time, succeeding pesticides can be even less efficacious than the competitors were when entering the market. Industry in other fields of technology has the need to constantly provide improved products in order to outmatch cheaper generic versions. This privileged position brings along two objections; one is the issue of sustainability, and the second queries if we are creating an incentive for inventors to come up with inventions that will be useless as time goes by?

First, the issue of sustainability. Exploiting pesticides to the fullest while holding a patent will increase pest resistance and thus oblige farmers to buy newly developed branded pesticides in the future. In the extreme case there would be continuously no competing useful pesticides in the public domain that the agrochemical industry would have to outmatch in order to be able to sell its branded products. This outcome is against the purpose of the patent system and is a path that can be only exploited by a small number of industries. Generally generic products serve as a threshold line that industry has to surpass by offering products of superior quality, original design, superior performance, lower environmental footprint, compatibility with other products or increased functionality. In case branded products do not display additional characteristics worth the markup price, consumers will opt for generic products. Under usual circumstances this fictive threshold line is raised as knowledge enters the public domain and improved generic products become available. Pesticide resistance reverse this trend by lowering this threshold line due to loss of effectiveness of generic pesticides. The logic of patents fails here as science is driven in a direction where advances are not leading forward but "running a treadmill". Those engaged in science and technology development benefit from a number of exemptions and bonuses, ranging from tax breaks to government investments, for their presumed constructive role in society. If the promotion of social welfare is the goal of such measures, it will be wiser to spend these resources incentivizing the other components in integrated pest management: breeding of plants with higher pest resistance, developing prophylactic measures and improving pesticide application technologies.

Second, we have to ask ourselves what the consequences of this example of an abusive practice are. What happens if others follow suit? Besides pesticides and antibiotics, there are not many more inventions that become useless due to changes in the environment. Now, we may still ponder if there is a fundamental difference between a technology that is "terminated" by a changing surrounding and a technology that is designed to terminate itself? If society blindly accepts the privileged position of the pesticide industry, does it make designing inventions to have a short life more acceptable? Especially the seed industry is already pushing forward such type of inventions. So-called "terminator genes" have the target of stopping a plants ability to reproduce thus making the buying of new branded seeds necessary (Eaton et al. 2002; Bustos 2008). The recollection of seeds for the next harvest becomes useless.

In last few years we have observed a re-emergence of scholarship condemning built-in obsolescence in technological products (especially electronic devices) with a strong emphasis on ecological effects (cf. Guiltinan 2009). The general push toward sustainability has to condemn wastage in all industries.

\section{Conclusion: Implications for global justice and future generations}

Many experts welcome a reduction of pesticides use. Current levels of pesticides use are having negative effects on soils, alternative farming practices and public health (cf. McIntyre et al. 2009; Atreya et al. 2011; Muñoz Quezada 2011). Nevertheless, if pesticides effectiveness is considered a common heritage of humankind, the deliberate continuous exclusion of a particular group (i.e. the global poor and future generations) without their consent from access to such a good is condemnable. The more when this may lead to permanent exclusion. Some type of compensation for having been excluded is owed to those left empty-handed. 
There are some reasons to believe that many farmers in developing countries would welcome compensation for using alternatives to pesticides. Much of the negative consequences of pesticide use are felt throughout the developing world. Insufficient regulation for both the use of pesticides and workers' safety protection is one of the main causes. Unrelatedly, we find a higher unemployment and underemployment rate in developing countries. Alternatives to pesticides are often more labour intensive and are thus less attractive for many developed world settings and large industrial farms in the Global South. Labour intensity per se is not a problem in the Global South, especially when it comes with the benefit of being self-sustainable (cf. Lenné 2000). Agroecological and organic farming techniques hardly rely on industrial pesticides, but come at the cost of being more labour intensive. Taking into consideration purchasing power parity, it also becomes evident that the economic cost of imported pesticides comes as a greater burden to most farmers in the Global South (cf. Nicholls and Altieri 1997).

While the farming communities that find those alternative pest control techniques attractive have the same right to use chemical pesticides than any other farmer, everyone would benefit if these communities choose differently. If using such techniques does not come to a disadvantage for these communities, there is no problem in incentivizing them to do so. To reduce pesticide resistance one could think about rewarding communities that use alternative pest control methods. Chemical pesticide users would not owe communities who never have thought about using synthetic pesticides any type of compensation, since in practice the latter are not being deprived. However, if the developed world overwhelmingly benefits from the use of an exhaustible resource that others help to conserve, moral decency would demand some type of acknowledgment.

Pesticides remain a much-appreciated emergency resource. When pests start to make massive damage, agricultural ministries and international organizations often try to combat these pests with chemical pesticides. Even though farmers are not regularly using chemical pesticides they have a substantial interest in these retaining their effectiveness in cases of major pests outbreaks.

Concerning future generations, one will have to concede the benefit of doubt to the prospect of new pesticide development being finite. Losing our capacity to combat pests may have devastating effects on future food security. Sustainable development makes it mandatory to give future generations the same opportunities to secure their basic needs.

Despite not having offered solutions for the problem raised by pesticides and exclusive rights, it has become clear, that the patent bargain is not possible to attain. Intellectual property may incentivize mismanagement of a precious exhaustible resource that we need to conserve for future generations. Having discovered the pesticidal traits of a chemical does not lead to a right to reckless exploitation.

Acknowledgments: This article is in part result of a research project of the Centre for Society and the Life Sciences in The Netherlands, funded by the Netherlands Genomics Initiative, and a postdoctoral fellowship at the Jacques Loeb Centre for the History and Philosophy of the Life Sciences. I greatly benefited from discussions with Henk van den Belt and comments made by the participants of the First International Conference of the Asia-Pacific Society for Agricultural and Food Ethics in Bangkok and the anonymous reviewers for the elaboration of this paper.

\section{References}

Atreya, K., Sitaula, B. K., Johnsen, F. H., \& Bajracharya, R. M. (2011). Continuing issues in the limitations of pesticide use in developing countries. Journal of Agricultural and Environmental Ethics, 24(1), 49-62.

Belt, H. v. d. (2010). Robert Merton, Intellectual Property, and Open Science. In H. Radder (Ed.), The commodification of academic research : science and the modern university (pp. 187-230). Pittsburgh: University of Pittsburgh Press. 
Berenbaum, M., Brusseau, M., Dipietro, J., Goodman, R., Gould, F., Gunsolus, J., et al. (2000). The future role of pesticides in US agriculture. Washington, D.C.: National Academy Press.

Bessen, J., \& Meurer, M. J. (2008). Patent Failure: How Judges, Bureaucrats, and Lawyers Put Innovators at Risk. New Jersey: Princeton University Press.

Biagioli, M. (2006). Patent republic: Representing inventions, constructing rights and authors. Social Research: An International Quarterly, 73(4), 1129-1172.

Böhme, G., Van Den Daele, W., Krohn, W., Hohlfeld, R., \& Schäfer, W. (1976). Finalization in science. Social Science Information, 15(2-3), 307-330.

Brody, B. A. (2010). Intellectual property, state sovereignty, and biotechnology. Kennedy Institute of Ethics Journal, 20(1), 51-73.

Bustos, K. (2008). Sowing the Seeds of Reason in the Field of the Terminator Debate. Journal of Business Ethics, 77(1), 65-72.

Butler, J. (2011). Who Owns Kafka? London Review of Books, 33(5), 3-8.

Carlucci, J. (1994). Reforming the Law on Pesticides. Virginia Environmental Law Journal, 14, 189224.

Chapman, A. R. (2009). Towards an Understanding of the Right to Enjoy the Benefits of Scientific Progress and Its Applications. Journal of Human Rights, 8(1), 1-36.

Chemillier-Gendreau, M. (2002). The Idea of the Common Heritage of Humankind and its Political Uses. Constellations, 9(3), 375-389.

Damalas, C. A., \& Eleftherohorinos, I. G. (2011). Pesticide Exposure, Safety Issues, and Risk Assessment Indicators. International Journal of Environmental Research and Public Health, $8(5), 1402-1419$.

De Jonge, B. (2011). What is Fair and Equitable Benefit-sharing? Journal of Agricultural and Environmental Ethics, 24(2), 127-146.

De Schutter, O. (2009). International trade in agriculture and the right to food. Geneva: FriedrichEbert-Stiftung.

den Hond, F. (2003). Innovation in the Agrochemical Industry. In F. den Hond, P. Groenewegen, \& N. M. van Straalen (Eds.), PESTICIDES: Problems, Improvements, Alternatives (pp. 53-76). Oxford: Blackwell.

Donselaar, G. v. (2009). The right to exploit : parasitism, scarcity, basic income. Oxford ; New York: Oxford University Press.

Eaton, D., van Tongeren, F., Louwaars, N., Visser, B., \& Van der Meer, I. (2002). Economic and policy aspects of 'terminator' technology. Biotechnology and Development Monitor, 49, 1922.

Frisvold, G. B., \& Reeves, J. M. (2010). Resistance Management and Sustainable Use of Agricultural Biotechnology. AgBioForum, 13(4), 343-359.

Glare, T., Caradus, J., Gelernter, W., Jackson, T., Keyhani, N., Köhl, J., et al. (2012). Have biopesticides come of age? Trends in biotechnology, 30(5), 250-258.

Gliessman, S. R. (2007). Agroecology: the ecology of sustainable food systems. Boca Raton: CRC Press.

Goeschl, T., \& Swanson, T. (2003). Pests, plagues, and patents. Journal of the European Economic Association, 1(2 - 3), 561-575.

Gosseries, A., \& Meyer, L. H. (Eds.). (2009). Intergenerational justice. Oxford \& New York: Oxford University Press.

Guiltinan, J. (2009). Creative destruction and destructive creations: environmental ethics and planned obsolescence. Journal of Business Ethics, 89(1), 19-28.

Headley, J. C. (1968). Estimating the productivity of agricultural pesticides. American Journal of Agricultural Economics, 50(1), 13-23.

Holling, C. S. (1973). Resilience and stability of ecological systems. Annual review of ecology and systematics, 4, 1-23.

Jefferson, O. A., Kollhofer, D., Ehrich, T. H., \& Jefferson, R. A. (2013). Transparency tools in gene patenting for informing policy and practice. [Feature]. Nature Biotechnology, 31(12), 10861093.

Khater, H. F. (2012). Prospects of Botanical Biopesticides in Insect Pest Management. Pharmacologia, 3(12), 641-656.

Lema, M. A., \& Lowenstein, V. (2008). Tit for tat: Agbiotech intellectual property and corporate social responsibility. Bridges Trade BioRes Review, 2(3),

Lenné, J. (2000). Pests and poverty: the continuing need for crop protection research. Outlook on AGRICULTURE, 29(4), 235-250. 
Littmann, J. (2014). Antibiotic resistance and distributive justice. PhD thesis, Department of Philosophy, University College London,

Macfarlane, B., \& Cheng, M. (2008). Communism, Universalism and Disinterestedness: Re-examining Contemporary Support among Academics for Merton's Scientific Norms. Journal of Academic Ethics, 6(1), 67-78.

Marks, S. P. (2011). The neglected human right to benefit from scientific progress: implications for human development. Paper presented at the Human Development and Capabilities Association 2011 International Conference, Den Haag, September 6-8

McIntyre, B. D., Herren, H. R., Wakhungu, J., \& Watson, R. T. (2009). International assessment of agricultural knowledge, science and technology for development (IAASTD): synthesis report with executive summary: a synthesis of the global and sub-global IAASTD reports. Washington, DC: Island Press.

Merton, R. K. (1942). Science and technology in a democratic order. Journal of legal and political sociology, 1(1-2), 115-126.

Montesinos, E. (2003). Development, registration and commercialization of microbial pesticides for plant protection. International Microbiology, 6, 245-252.

Muñoz Quezada, M. a. T. (2011). Aspectos bioéticos en el control y aplicación de plaguicidas en Chile. Acta bioethica, 17(1), 95-104.

Nicholls, C. I., \& Altieri, M. A. (1997). Conventional agricultural development models and the persistence of the pesticide treadmill in Latin America. The International Journal of Sustainable Development \& World Ecology, 4(2), 93-111.

Noonan, D. S. (2003). An economic model of a genetic resistance commons: effects of market structure applied to biotechnology in agriculture. In R. Laxminarayan (Ed.), Battling Resistance to Antibiotics and Pesticides: An Economic Approach (pp. 263-287). Washington, DC: Resources for the Future.

Orzech, K. M., \& Nichter, M. (2008). From resilience to resistance: Political ecological lessons from antibiotic and pesticide resistance. Annual Review of Anthropology, 37, 267-282.

Outterson, K. (2005). The vanishing public domain: antibiotic resistance, pharmaceutical innovation and intellectual property law. University of Pittsburgh Law Review, 67, 67-123.

Outterson, K. (2014). New Business Models for Sustainable Antibiotics. Centre on Global health Security Working Group Papers, Working Groups on Antimicrobial Resistance, Paper 1. London: Chatham House (The Royal Institute of International Affairs).

Palumbi, S. R. (2001). Humans as the world's greatest evolutionary force. Science, 293(5536), 17861790.

Pimentel, D., Acquay, H., Biltonen, M., Rice, P., Silva, M., Nelson, J., et al. (1992). Environmental and economic costs of pesticide use. BioScience, 42(10), 750-760.

Popp, J., Petö, K., \& Nagy, J. (2013). Pesticide productivity and food security. A review. Agronomy for Sustainable Development, 33(1), 243-255.

Quinn, R. (2013). Rethinking Antibiotic Research and Development: World War II and the Penicillin Collaborative. American journal of public health, 103(3), 426-434.

Radder, H. (2013). Exploring Philosophical Issues in the Patenting of Scientific and Technological Inventions. Philosophy \& Technology, 26(3), 283-300.

Schneider, I. (2010). Das Europäische Patentsystem. Wandel von Governance durch Parlamente und Zivilgesellschaft. Frankfurt am Main \& New York: Campus.

Singer, P. (2004). One world: the ethics of globalization. (2nd ed.). New Haven \& London: Yale University Press.

Stephan, P. E. (2012). How economics shapes science. Cambridge, MA \& London: Harvard University Press.

Sterckx, S. (2005). The ethics of patenting: uneasy justifications. In P. Drahos (Ed.), Death of patents (pp. 175-211). Oxford: Lawtext Publishing.

Stetter, J., \& Lieb, F. (2000). Innovation in crop protection: trends in research. Angewandte Chemie International Edition, 39(10), 1724-1744.

Stiglitz, J. E. (2008). Economic Foundations of Intellectual Property Rights. Duke Law Journal, 57, $1693-1724$.

Strahilevitz, L. J. (2005). The right to destroy. The Yale Law Journal, 114, 781-854.

Timmermann, C. (2014a). Limiting and facilitating access to innovations in medicine and agriculture: a brief exposition of the ethical arguments. Life Sciences, Society and Policy, 10(8).

Timmermann, C. (2014b). Sharing in or benefiting from scientific advancement? Science and engineering ethics, 20(1), 111-133. 
Timmermann, C., \& Belt, H. v. d. (2013). Intellectual property and global health: from corporate social responsibility to the access to knowledge movement. Liverpool Law Review, 34(1), 47-73.

UN Committee on Economic, Social and Cultural Rights (2006). General Comment No. 17: The Right of Everyone to Benefit from the Protection of the Moral and Material Interests Resulting from any Scientific, Literary or Artistic Production of Which He or She is the Author (Art. 15, Para. 1 (c) of the Covenant, E/C.12/GC/17).

United Nations (1948a). 150th Meeting, held on Saturday, 20 November 1948 (A/C.3/SR.360). In r. S. General Assembly, 3rd Committee (Ed.). Paris: United Nations.

United Nations (1948b). 151st Meeting, held on Monday, 22 November 1948 (A/C.3/SR.361). In r. S. General Assembly, 3rd Committee (Ed.). Paris: United Nations.

Waibel, H., Zadoks, J. C., \& Fleischer, G. (2003). What Can We Learn from the Economics of Pesticides? In R. Laxminarayan (Ed.), Battling Resistance to Antibiotics and Pesticides: An Economic Approach (pp. 137-157). Washington, DC: Resources for the Future.

Wenar, L. (2011). Rights. In E. N. Zalta (Ed.), Stanford Encyclopedia of Philosophy (Fall 2011 Edition).

Wilson, J. (2013). Drug Resistance, Patents and Justice: Who Owns the Effectiveness of Antibiotics? In J. Coggon, \& S. Gola (Eds.), Global Health, Global Goods, and International Community (pp. 151-164): Bloomsbury Academic.

WIPO (2013). Patents. Frequently Asked Questions. http://www.wipo.int/patentscope/en/patents faq.html. Accessed August 10, 20132013. 